\title{
Analytical Assessment of the Common Writing Errors among Saudi Foundation Year Students: A Comparative Study
}

\author{
Amal Ibrahim Shousha ${ }^{1}$, Nahed Moussa Farrag ${ }^{1} \&$ Abeer Sultan Althaqafi ${ }^{1}$ \\ ${ }^{1}$ English Language Institute, King Abdulaziz University, Jeddah, Saudi Arabia \\ Correspondence: Amal Ibrahim Shousha, English Language Institute, King Abdulaziz University, Jeddah, Saudi \\ Arabia.
}

Received: June 7, 2020

Accepted: June 24, 2020

Online Published: July 10, 2020

doi: $10.5539 /$ elt.v13n8p46

URL: https://doi.org/10.5539/elt.v13n8p46

\begin{abstract}
This research explored the most common writing errors of Science and Arts students of the Foundation year program at a Saudi University that hinder them from achieving their course goals, learning outcomes and becoming efficient writers. The importance of this research stems from the fact that, it is a comparative study that shows the differences in writing errors between Science and Arts students and relates writing difficulties to students' background education, family support, level of the language and teacher's feedback techniques. It unveils the causes of writing errors and suggests suitable remedies from teacher's perspectives. The findings can be useful for teachers, students and course designers.
\end{abstract}

Keywords: Error analysis, interlingual and intralingual errors, L1 interference, teaching material, feedback

\section{Introduction}

Writing is an effective tool for language development and for critical thinking in all disciplines. It is an active and productive skill of language use essential for professional and academic success (Al-Ghobra, 2019). Academic writing skills are considered to be crucial for students to fully express themselves and to continue their university education. Thus, it is "an essential aspect of the curriculum of English as a major, and for academic purposes" (Swalmeh, 2013, p.2).

However, writing a well-developed, correct piece of writing is not an easy task in one's first language (L1), not to mention in a second (ESL) or foreign language (EFL). In the current context, most native Arabic speaking students, Saudi students being no exception, face problems in writing complete correct sentences. Inability to express their ideas well in English is possibly another reason for their writing problems. "Many students are able to understand the language, but most of the students face problems while communicating their ideas effectively" (Hafiz et al., 2018, p. 113). They are "incompetent in using their language" (Alkubaidi, 2019, p. 152) and "low proficient in writing composition" (Siddiqui, 2015, p. 233).

Writing errors occur due to several reasons: "English is not the means of instruction in the educational system of Saudi Arabia, the students are less exposed to English in daily or academic communication, and they are weaker at English, especially in writing skills" (Al haysony, 2012, p. 64) and the lack of the social aspects of writing; authentic purpose, audience and context (Alkubaidi, 2019). This is in addition to the importance given to teaching reading and listening at the expense of writing (Huwari \& Al-Khasawneh, 2013). In fact, these reasons can reduce the student's ability to deliver a cohesive and contextual content, write grammatically correct sentences and that could negatively affect the outcomes of students' academic life.

Thus, the study and analysis of student's errors in writing has been an interesting and productive field for a large number of researchers and has become an increasingly important area in applied linguistics. There has been a number of previous studies that have examined writing errors produced by foreign English language students including Saudi students. A detailed illustration of some of these papers is given in the literature review section. However, to the researchers' knowledge no current study has investigated student's writing errors from the perspectives of both students and teachers. Therefore, it is essential to investigate the most common types of errors in the Saudi students' writing, and their causes, then suggest solutions in light of the perspectives of both students and teachers.

The aim of this study is to investigate the common writing errors of Saudi female students of the two main 
disciplines; Science and Arts sections, in the English subject of the foundation year at a Saudi university showing the causes and remedies of these errors from the perspectives of both students and teachers. By so doing, administrators are encouraged to foster change in course books to cater for these errors and teachers are urged to adapt their teaching methodologies to help students improve their writing skills. Thus, the present study is an attempt to fill the literature gap by considering the student's common writing errors from different perspectives.

The research questions are:

1. What are the student writing difficulties and the effective feedback techniques as experienced by students and teachers?

2. What are the most common writing errors peculiar to Science in comparison to Arts students as shown in their writing samples?

3. What are the sources of these writing errors from the teacher's perspectives?

4. What are the solutions to eliminate these writing errors from the teacher's perspectives?

The section that follows reviews the literature related to previous related research studies in the field of error analysis and further explores literature related to a more specific Saudi EFL context.

\section{Review of Literature}

This section is subdivided into two parts. The first part seeks to primarily demonstrate previous literature for error analysis' definitions, sources, process, and highlight the importance of the current research. The second part of this literature review section contextualizes the research by providing background information on writing error research in the Saudi context. The importance of this section stems from the fact that it provides valuable findings to compare this research's results to and therefore valid conclusions and practical recommendations can be reached.

\subsection{Error Analysis: Definition, Approaches, Sources, Process and Importance}

Errors are essential part of language learning. The making of errors is a device the student uses in order to learn his first language or his second / foreign language. According to Corder (1981), "the making of errors then is a strategy employed both by children acquiring their mother tongue and by those learning a second language." (p. 11). Essentially, it is an integral part of learning. What the student speaks or writes is not an inadequate or incorrect form of the target language "but a peculiar transitional idiolect, which should be approached in the same way as the language of an infant or some unknown language." (Corder, 1981, p. 34). These errors cannot be corrected by the student because they emanate from some unfamiliarity of the target language rules rather than a reluctance in applying them. Thus, making errors in language learning is "inevitable" (Brown, 2000) rather than being "signs of failure" (Al-husban, 2018). Errors are considered to be "red flags" which demonstrate problems. Brown (2000) argued further that the students' acquisition process will be hindered if they neither make errors nor receive any feedback on them.

There are two types of errors: systematic and non-systematic errors. Systematic errors are competence errors, which show the level of competence of the student. Contrarily, non-systematic errors are identified as errors of performance, which could be a result of both internal and external factors. They can be considered as mistakes caused by memory lapses, lapses, tiredness, or physiological conditions. Students, in most cases, are able to correct these mistakes independently. This shows the difference between student errors (systematic) and mistakes (non-systematic type of errors). In this research, the focus of interest is on systematic or competence errors as studying these errors is an important step in minimizing or overcoming them.

In the field of Applied Linguistics, there are three theories for students' errors. The first one is the Contrastive Analysis Theory (CA) which advocates the idea that students' errors are a result of their mother language interference and that teaching materials should focus on the differences between target language and native language. Opponents of CA assert that other factors could perhaps, cause students' errors and that these factors are not limited to L1 interference. These factors include, but are not limited to psychological and pedagogical aspects.

The second approach to students' errors is the Error Analysis (EA) approach. This approach was established in the 1970s by Corder and his colleagues. EA is defined as "a type of linguistic analysis that focuses on the errors students make. It consists of a comparison between the errors made in the target language and that target language itself." (Khansir, 2012, p. 1029). It is "the process of studying the appearance, nature, causes and consequences of unsuccessful language" (Hafiz et al., 2018, p. 113). It is a reaction to contrastive analysis as it is not limited exclusively to focusing on L1 errors. Error Analysis (EA) is broader in the sense that its objective is 
to concentrate on all types of errors and subsequently attempt to tackle their causes and consequences on language production.

Khansir (2012) highlights the difference between contrastive analysis and error analysis where: "Contrastive analysis starts with a comparison of systems of two languages and predicts only the area of difficulty or error for the second language student, whereas error analysis starts with errors in second language learning and studies them in the broader framework of their sources and significance" (p. 1029). Accordingly, error analysis outcomes are more efficient in developing teaching materials and methodologies. Furthermore, the role of the student as an active participant is stressed in this approach.

To wit, CA is an approach used to explain ESL/EFL students' errors based on comparison of L1 and L2 to determine similarities and differences. This approach advocates the idea that errors are a result of the influence of the native language. Unlike CA, EA not only focuses on errors caused by students' L1 interference, but also the errors which occur in a students' mind during the process of constructing L2. This could be due to a deficiency in learning rules of the target language or, in applied linguistics terms, overgeneralization.

According to Corder (1981), EA has two functions: pedagogical (theoretical) and practical (diagnostic). The pedagogical function investigates the language learning process. The practical aspect, on the other hand, relates to "guiding the remedial action we must take to correct an unsatisfactory state of affairs for student or teacher." (p. 45). These two aims are highlighted by many researchers like Al-husban (2018) who believes EA's importance is to "identify what students still need to learn; and how to improve their process of learning; the strategies and methods they should use when learning the language; why students add, omit, use wrong forms or words, or disorder structures and sentences; and how to eliminate the use of the mother language in learning a second language.” (p. 29).

Researchers agree that EA of students' writing samples is useful for teachers, students and researchers (Noor, 1996; Khansir, 2012; Corder, 1967 \& 1981). Students' errors are significant as they show the teacher "how far towards the goal the student has progressed and consequently, what remains for him to learn." (Corder, 1967, p. 167). Notably, "It is on the basis of the information the teacher gets from errors that he varies his teaching procedures and materials, the pace of the progress, and the amount of practice which he plans at any moment" (Corder,1981, p. 35). In this sense, teachers are not error hunters (Alhaysony, 2012). Regarding students, making errors is a device they use to learn. Teacher's feedback will be more instructive for both students and teachers if, students try to discover the right form independently. In addition, these errors provide researchers with insights into how language is learned or acquired and the strategies that students use in their discovery of the language.

The third approach to students' errors refers to interlanguage as a system that students build for themselves that is different from the target language and the first language. It is a system that has its own peculiar characteristics and rules. Selinker (1972) coined the term interlanguage which entails that the student's language is a hybrid between his first language (L1) and the target language based on the fact that a large number of errors could be ascribed to the process of transfer which happens when "...the idiosyncratic sentences of a second language student bear some sort of regular relation to the sentences of his mother tongue."(Corder, 1981, p. 24) This transfer is natural as L1 is the language that the student knows very well and as language learning is closely related to language transfer. (Abdullah, 2017; Qaid \& Ramamoorthy, 2011).

Language transfer can be positive or negative. If there are similarities between L1 and the target language, the transfer is positive in the sense that it helps and accelerates progress learning the target language (Qaid \& Ramamoorthy, 2011). The negative transfer occurs when there are differences between the two languages. What occurs is that "while students are trying to learn a second language's rules. The only language they are fully familiar with is their own language, so they transfer their own grammatical rules into the target language and make errors" (Alhaysony, 2012, p. 64). The term L1 negative interference is used when the language elements of L1 cause linguistic inadequacies in learning L2. These L1 errors will become less frequent in advanced proficiency stages i.e. with high level students (Alasfour, 2018).

On the other hand, intralingual errors are developmental errors and often represent incomplete learning of L2 rules or overgeneralization of them. They are errors caused by the target language itself due to various sources: incomplete rule application (simplification of complicated rules), overlooking the exceptions to rules, overusing the rules or overgeneralization in a way where teachers explain the language but do not give correct models of the target language.

Arabic and English originate from two different language families; Semitic and Indo - European respectively. Therefore, there are differences in the grammatical structures between them. This difference is the reason behind many writing errors; where the Arabic language negatively interferes with achieving a desired progression of the 
target language, the target language in this case being English. Odlin (1989) classifies this negative transfer into four types: underproduction (avoidance of using relative clauses), overproduction (the use of simple sentences), production errors (substitutions, calques and alterations of structure types of errors), and misinterpretation. Transfer can be affected by individuals' experience, aptitude for learning languages and proficiency level.

Other sources for writing errors are the context of learning, and communication strategies (Corder, 1974), ignorance of the correct pattern, deficient teaching or inadequate practice (Khansir, 2012), overgeneralization, ignorance of rule restriction, incomplete application of rules, false concepts hypothesized (Richards, 1971 as quoted in Khansir, 2012) and weakness or failure of memory (Gorbet, 1979).

Regarding the process of EA, Corder's model (1981) is the most implemented among the EA models for writing error analysis. It has three simple steps as follows:

1. Collection of sample errors/writing samples

2. Identification of errors

3. Description of errors

This model of EA illustrated above is adopted in this research in the analysis and study of students' writing errors.

As for the efficacy and importance of EA, it is effective in ordinary teaching as well as in planning remedial teaching. In ordinary teaching, it helps the improvement of language teaching materials and methods (Corder, 1967; Richards et al., 1992). Khansir (2012) highlights how teachers can make good use of error analysis results in the classroom by:

- Devising remedial measures,

- Preparing a sequence of target language items in classrooms and textbooks with the difficult items coming after the easier ones,

- Making suggestions about the nature or strategies of second language learning employed by both first and second language students (p. 1029).

EA results help teachers to correct their errors, improve their teaching and focus on areas that need reinforcement (Alhaysoni, 2012; Swalmeh, 2013).

Teachers can be given criteria to understand and evaluate potential areas of difficulty and thus appreciate students' errors where the mother language interferes with the target language learning. With this understanding, teachers can make students understand the origin of their errors (Corder, 1981). They can improve students' confidence "by their teaching strategies, giving them correction feedback and making students aware that making grammatical errors and mistakes should not discourage them from writing" (Atashian \& Al-Bahri, 2018, p. 144). In this non-threatening classroom atmosphere in which errors are treated as a sign of learning, criticizing students' composition should be avoided and instead praising their achievements is vital (Alhaysoni, 2012). That is to say, the effective teaching methodology plays an important role in the way students perceive the writing process (Alkubaidi, 2014). Furthermore, encouraging students to recognize that making errors is a part of effective learning as well as a sign of progress, could be more effective if integrated with students' motivation and intelligence in remedying potential errors.

The second part of this review focuses on research investigating writing errors by Saudi students, their causes and suggested remedial actions.

\subsection{Writing Error Research in the Saudi Context}

A number of research studies have been conducted to analyze students' writing errors, including Arab EFL students. Nine research papers have been selected as the core of this review as they are among those which focused on writing errors made by Saudi students, which in essence is the focus of this research paper.

Alkubaidi's (2019) research explored both student and teacher's perceptions regarding students' writing and the writing curricula used in a Saudi university classroom. It followed an action research design which had three main phases: exploration (observation of students), intervention of a series of writing workshops for students, and reflection of both teachers and students on this experience.

In the exploration stage, it was found that students lacked the basic ability to construct simple sentences but at the same time they enjoyed free writing. Moreover, the use of innovative teaching methods was limited due to lack of time and that student with a private schooling academic background had higher proficiency levels. Collaborative working was used by teachers due to time constraints in completing the work and learning about 
each student's practice was found to be a positive. Students also liked the use of technology in writing. Finally, students found college materials dull and repetitive.

Data taken from the three stages showed that firstly, students used compensational strategies (memorization of paragraphs) to make up for lack of learning. Secondly, teachers criticized the attitude of students and blamed them without trying to make the material enjoyable. Thirdly, the teaching approach did not foster learning because it was outdated. Finally, teachers needed to build confidence among students by enhancing their language abilities. The study concluded that improving the language learning system and the quality of teaching and learning in the Saudi language classroom would help minimize potential difficulties.

Another study conducted by Hafiz et al. (2018) explored the most common syntactic errors made by preparatory year students at Jazan University, Saudi Arabia. It was found that copula (the absence of the verb), subject-verb agreement, tense, infinitive, articles, prepositions and conjunctions were the most common problematic areas. The research study attributed these errors to the lack of practice and interference of the first language. Recommendations included improving the curriculum, having practical classrooms, giving ample time to activities that help learning. Also, teachers were recommended to have more focus on students' performance, encourage the students and use English exclusively in classrooms.

Alasfour (2018) investigated the L1 transfer on Arabic students in the ESL context. She used both CA and EA methods to determine the errors and their causes. She analyzed 50 papers and interviewed five students. She found that errors in descending order were in formulating relative clauses, the passive voice and the definite articles. She also found no difference between the frequency of transfer and non-transfer errors, despite L1 transfer errors being found to be quite common. She recommended familiarizing teachers with possible sources of errors of students. Teachers were also recommended to encourage conducting error analyses and adapt a CA informed means of instruction to help students reduce and overcome errors.

In the same vein, Ababneh (2017) investigated specific types of errors made in the writing samples of 50 English major female students in Tabuk University, Saudi Arabia. The research study investigated their causes and suggested suitable remedies. Errors were categorized into: grammar, syntax, and substance or word choice. The study concluded that the majority of errors fell in the grammar (tenses, singular/plural, articles), syntax (subject-verb agreement) and substance (spelling) categories. The causes mentioned were lack of conversation in English, lack of reading in English and influence of the Arabic language. Recommendations included improvement of course syllabus and supplementing this with a variety of teaching strategies and methods to overcome these errors.

Similarly, the main focus of Alhaysony's research (2012) was to analyze article errors done by female students at the English Department, Ha'il University. Omission of articles errors were the most frequent and substitution errors were the least frequent. The sources of these errors were more interlingual than intralingual. Proposed solutions included sufficient practice of English writing and a proper method of teaching English grammar and the rules and conventions of writing.

Sawalmeh's research (2013) was carried out in the same Ha'il Univeristy. It also advocated that most of students' errors in EFL writing were due to L1 transfer. This is based on the results of his research which investigated the errors committed by 32 male university students studying in the preparatory year program in Ha'il, Saudi Arabia. The errors were in the areas of: verb tense, word order, subject/verb agreement, pronoun, spelling, capitalization, preposition, article, double negative and sentence fragment. The study recommended that language teachers should collect these errors and ask students to analyze and correct them if possible.

In addition, Huwari \& Al-Khasawneh (2013) explored the writing weaknesses among preparatory year male students at Taiba University. The study was a qualitative research based on students' responses in a semi-structured interview for gathering data. Students stated that their weaknesses were in four areas: grammar, knowledge and understanding of the writing topic, writing practice, and educational background. Researchers recommended that the English curriculum should focus on these areas and on writing as a skill in much the same way it focuses on reading and listening and that there should be more writing practice in and out of the classroom.

Errors of capitalization in the writing of twenty Saudi female students were evaluated regarding ten capitalization categories set by Siddiqui (2015). Observation of students' writing and interviews of ten students were done to reach comprehensive reasons relating to capitalization errors. Results showed that capitalization errors were one of the significant areas of errors in EFL writing among Saudi students across all the ten categories. The highest percentage of errors was in category nine which focused on malformation of individual letters. Causes of these errors were attributed to interlingual and intralingual reasons. Students believed that they 
made capitalization errors due to time restrictions and limitations for a writing task. An overemphasis on focusing heavily on grammar rules at the expense of writing and forgetting the rules of capitalization whilst undertaking writing tasks within a short time and training in school to support the development of practicing upper and lower case of letters. Siddiqui recommended that teachers specializing in teaching writing skills should focus on capitalization. One of the suggestions to teach this skill in class would be to provide focused feedback on capitalization. It was also suggested that capitalization corrective activities should be given in class along with making the writing classes more engaging in actual writing practice rather than teachers academically lecturing students on how to write, and provide students with individual student solutions to address problem areas. The solutions suggested was for teachers to facilitate learning via set tasks in an engaging and error corrective sense.

Abdel-Fattah et al. (2018) is case study research which aimed to identify the reasons behind Saudi EFL university students' writing errors. The methodology of the mentioned research was to conduct an error analysis of writing samples of three male students in the European Languages Department. Errors were categorized into two main types; interlingual and intralingual under the following sub-categories: grammar, syntax, lexis, semantics, substance and organization. Students also responded to fifteen closed questions linked to problems students face while writing. The results showed that the number of intralingual errors exceeded the number of interlingual ones. Reasons provided were due to a difference between students' first language and target language and the poor level of students' competence. This called for a need to adopt teaching strategies and materials to promote the learning process. Looking up new words from dictionaries, independent self-correction, targeting some errors as goals to achieve over a certain period of time, and limiting the use of red pen were all ideas agreed upon by participants. It was recommended by the study's researchers to encourage students to publish their writing with an aim to write for an audience other than the class teacher and to keep a writing portfolio which includes previous writing drafts, and finally maintain dialogue journals. Teachers should also lessen the feeling of anxiety of students and give them more process practice in guided paragraph writing.

To conclude this section, the literature above identified some clear indicators where previous studies focused on investigating the common writing errors of Saudi students and their causes which is similar to the aim of the current study. Results, in the studies illustrated above, showed an inability of students in doing English writing tasks. The difficulties students faced in studies mentioned in this literature review demonstrated student's inability to construct simple sentences, grammar errors in tenses, singular and plural articles, verb absence, verb tense, to infinitive, articles, prepositions, double negative, and pronoun use. Moreover, results also showed student's general reluctance to learn more, and their memorization of the writing paragraphs. As for the most common syntactic errors, these included subject-verb agreement, conjunctions use, word order, and sentence fragment. Regarding, substance errors, these were mainly in the areas of spelling and capitalization categories. Causes of writing errors were attributed to interlingual (L1 transfer) and intralingual reasons. Furthermore, reasons peculiar to EFL contexts were identified where English was not the means of instruction in schools and universities, and a lack of exposure to English in conversation in daily and academic contexts. Other contexts related to EFL contexts were instances where students lacked reading in English, absence of the social aspects of writing (authentic purpose, audience and context), time constraints in practicing specific EFL skills. In fact, all these results and findings of previous research are significant as the errors made by students, in similar Saudi contexts, fell into the same writing categories tackled in this research; grammar, syntax and semantics, which made the comparison in the discussion section between our research findings related to errors, their causes, solutions and previous research more useful.

The following section is concerned with the methodology employed for this study. Section 4 analyzes the results gathered and addresses each of the research questions in turn. The final section discusses conclusions of the current study.

\section{Methodology}

This section discusses the research methods that were used, including the theoretical framework, research design and participants' selection method and background. In addition, an overview of instruments, data collection and analysis methods are illustrated.

\subsection{The Theoretical Framework}

To achieve research objectives, this study used the descriptive analytical approach based on Corder's model (1981) for EA as follows:

1. Identifying the common writing errors by analyzing the students' writing samples; 
2. Classifying the errors into different linguistic types and categories;

3. Computing the frequency of these errors;

4. Exploring the reasons behind these types of errors in the light of teaches and student's perspectives; and

5. Suggesting possible remedies for these errors.

This model was chosen as it includes a number of steps that ensures a comprehensive diagnosis of students' errors.

\subsection{Research Design}

The methodological approach taken in this study followed a descriptive quantitative research design to collect and analyze data. Data were collected using sampling methods, sending out online questionnaires to teachers and distributing paper questionnaires on students and hence turned into numbers, frequency percentages, and averages of which interpretation led to research results.

It seemed necessary for the researchers to have two groups of students from the two tracks of the university; Arts and Science tracks, to have a comprehensive overview of student errors. Furthermore, researchers tried to have random selection of teacher participants of different nationalities, cultural and educational backgrounds to ensure the validity of data collected by the questionnaire provided that almost all teachers had experience in teaching both the Arts and Science students. Hence, this varied group of teacher participants ensured in a way the validity of the data reached as it reflected different experiences with students and provided solid and varied solutions for the writing errors. In addition, the demographic information of both students and teachers helped us to understand the participants more which led to a more realistic interpretation of research results.

\subsection{Participants}

The participants of the study were two groups of 32 students each $(n=64)$; one from the Arts and the other from the Science track and a group of teachers $(\mathrm{n}=25)$ who experienced teaching both tracks several times before. Students were enrolled in the preparatory year program at a Saudi university in which the intensive English Language Course for 18 hours per week is a mandatory course. The results of the placement test determine the level that students join. Each level is for one module (seven weeks) and students have to pass four levels to specialize. The participants were in level 2 in the second module of the academic year 2018/2019. They studied two different books by Cambridge; English Unlimited, Special Edition Course Book for Art students and Unlock 2 Course Book for Science students. The content of the course books varied to match the needs of students and their level of English. The Science course book was more scientific oriented to match students specialization and prepare them for the scientific tasks needed in their faculties. On the other hand, the Arts content was more general as most of the students would be studying in Arabic in their faculties. Therefore, the type and length of the writing tasks differed in the two groups.

The demographic information of student participants showed that almost all of them have only lived in Saudi Arabia and had never resided in any foreign country except for short visits. They used Arabic at home. They were all native Arabic speakers in their early twenties educated at both public or private Saudi schools, with the majority having studied in governmental schools. The participants came from almost similar socioeconomic and educational backgrounds.

On the other hand, the nationalities of the 25 teacher participants were Saudi (11), Indian (3), Jordanian (2), Egyptian (3), British (1), American (1), Canadian (1), Pakistani (1), Tunisian (1), and Slovak (1). The educational background varied with the majority holding M.A degrees (15), B.A. (7) and PhD (3). Almost all of the teachers had a solid background in education and had undergone a number of professional development courses. Half of the teachers had between 11 and 20 years of experience, whereas $12 \%$ had over 20 years of experience.

\subsection{Instruments and Data Collection}

Data collection was done using a structured method and conducted on sufficient samples (64 students and 25 teachers) that can represent the entire population in the university. Therefore, three instruments were used in this research namely: end of module writing exam samples, teacher, and student questionnaires (devised by researchers).

As for the tasks given, Science students were given 50 minutes to write a well-developed argumentative paragraph on social media; "Young people spend too much time on social media. Do you agree or disagree? They were asked to write from 100 to 130 words. As for Arts students, they were asked to write at least one 
paragraph on the following topic: "You are going to travel with you family next month. Write an email to your friend telling her/him about your plans for the trip". Students were asked to write from 80 to 120 words. The tasks were compatible with the SLO's (student learning outcomes) expected from each group.

Identifying prominent writing errors in 64 samples of end of module writing exam was followed by the stage of determining types and frequencies of errors. A comparison between the types and frequencies of errors between Arts and Science students was made and inferences for the expected difference were reached.

As for the questionnaires, the student questionnaire was in Arabic. It had two sections: a section for demographic information and another section on writing difficulties and feedback techniques experienced by students. Students were asked to choose between "agree", "disagree" or "neutral" in relation to the statements provided. Writing difficulties statements were on generating ideas, vocabulary range, spelling and grammar errors, sentence structure and writing mechanics. There were two statements about individual feedback and whole class feedback.

Questionnaires were distributed at the end of the course. Prior to the students receiving the questionnaire, they were provided with comprehensive information about all aspects of the research project including its objective and its benefit to them and to future students. The paper-based questionnaire was used for students to make sure of their understanding of its items and also to guarantee their full participation. Students' responses were inserted manually into the questionnaire Google form created for this purpose to obtain descriptive statistics.

On the other hand, the link of the online questionnaire was sent to 50 teachers of which 25 filled it. The first part of the questionnaire included questions related to demographics; nationality, education and years of experience. The second part included closed and open questions. Teachers were asked if they agreed, disagreed or were uncertain regarding a list of student writing difficulties (almost the same writing difficulties in the student questionnaire) and whether these difficulties were faced by their students, and a list of their causes and solutions. Teachers were also asked to add their own input regarding other causes for student writing errors and to suggest additional remedies.

To ensure content validity of the questionnaires, they were given to experienced colleagues to review the questionnaire items to check whether they measured the intended collecting data relevant to the current research study. As a result, some modifications of wordings were made. In addition, the reliability of data (instrument) was tested by having two items of similar meaning to check whether participants' responses would be the same or not. These items were item No. 4 "carelessness" and item No. 12 "unwillingness to learn" among the causes of writing errors in the teacher questionnaire.

\subsection{Data Analysis}

Actual data enlisting students' errors is essential to find reasons for these errors as "a comparison of the native and target languages would be useful for explaining why certain errors arise, but in the absence of actual data about students' errors little if anything could be reliably predicted" (Odlin, 1989, p.19). Thus, the common writing errors of the Science and Arts students were identified and related to content (semantics), grammar and sentence structure (syntax), and spelling and punctuation (mechanics) categories based on the rubric for writing assessment used at our institute.

For intercoder reliability, only one researcher marked and analyzed both groups' writing papers for errors which were mainly verb form and tense, subject-verb agreement, pronoun, preposition, and article, spelling, punctuation, and wrong word errors. These errors were classified into categories. Then, the frequency of each error type was computed and its percentage related to the total number of errors was calculated for each section; Arts or Science. The average of the total number of errors in each section was also calculated.

Consequently, errors were described in an attempt to show their sources or causes and to suggest remedial actions based on the demographic information of students as well as student and teacher's perspectives as shown from their responses to questionnaires' items. Finally, conclusions were made by relating this research's findings to literature findings and further recommendations were suggested.

The following section attempts to answer research questions by showing and discussing the results reached from analyzing students' writing papers and administering questionnaires to both teachers and students.

\section{Results and Discussion}

4.1 To Answer the First Research Question Regarding the Writing Difficulties Experienced by Students and Their Preferred Feedback Techniques, Analysis and Discussion of the Results of Student and Teacher's Responses to the Questionnaires are Provided Below. 


\subsubsection{Student Questionnaire Results}

From analyzing student questionnaire results, it was found that almost three quarters of students of both sections came from governmental schools. About half of the Arts students has lived in Jeddah while the other half has lived in the suburban areas around Jeddah. Most of Science students had lived in Jeddah (96\%). This indicates that Science students had better access to bigger schools and better academic environment typical of an urban city. Moreover, $46 \%$ of Science students stated they got academic support from their families while a percentage of $38.5 \%$ of Arts students indicated that they received academic support from their families.

As for student language level, it was found that $80 \%$ of the Science section students got $90+$ in Level 1; while Arts students varied in their level of proficiency; half of them got grades between 65 and 77, while the other half got grades between 80 and 95 . These grades indicate that the Science class already had majority of high achievers

Student writing difficulties and preferred feedback techniques can be seen in the following table. The percentages represent the frequency of their positive response "agree" to the writing difficulties faced and feedback techniques used.

Table 1. Student writing difficulties and feedback techniques

\begin{tabular}{cccc}
\hline Writing Areas & Writing Difficulties & Science\% & Arts\% \\
\hline Semantic & It is difficult for me to write down my ideas & 30.8 & 73.1 \\
& I don't have enough vocabulary to express my ideas & 38.5 & 65.4 \\
$\begin{array}{c}\text { Grammar \& } \\
\text { Sentence Structure } \\
\text { (Syntax) }\end{array}$ & Most of my problems in writing are related to grammar and & 42.3 & 73.1 \\
& Sentence structure & & \\
& Verb conjugations are not understandable for me. & 7.7 & 61.5 \\
(past/present) & I mix up sentences & 15.4 & 61.5 \\
& I can connect sentences and ideas together (use and, but, & 46.2 & 61.5 \\
Mechanics & because) & 11.5 & 57.7 \\
& Punctuation marks are a real problem for me & 30.7 & 69.3 \\
Feedback & I always have a lot of spelling mistakes in writing & 42.3 & 57.7 \\
& I get feedback individually from my teacher & 38.5 & 96.1 \\
& I benefit from revising my mistakes in writing as a group in \\
class & & \\
\hline
\end{tabular}

As the above table shows, the problem which received the highest percentage in the Science section was connecting ideas together $(46.2 \%)$ whereas the highest percentages in the Arts section were related to problems like expressing students' ideas (73.1\%) and writing grammatically well-structured sentences $(73.1 \%)$. Thus, difficulties experienced by the Science students were mainly syntactic problems whereas the Arts student's problems were more semantic (expressing their ideas), grammar, sentence structure and mechanic problems (spelling 69.3\%). This inability of students to express their ideas in this research was also voiced by the students in Huwari \& Al-Khasawneh (2013) and Hafiz et al. (2018) "My students are able to understand the language, but most of the students face problems while communicating their ideas effectively" (p. 113). However, the difficulties faced by the Science students which were more syntactic and the lower percentage of students who faced the writing difficulties if compared to Arts students percentages reflected their higher proficiency level than their colleagues in the Arts section. This was ensured by their grades in Level 1 which were significantly better than Arts students' grades as mentioned above. Also, the better educational opportunities and greater family support given to Science students justified their higher level of language proficiency compared to Arts' students.

As for the feedback on writing errors, Arts students received more individual feedback from their teachers than Science students $(57.7 \%)$ to $(42.3 \%)$ respectively. In addition, the percentages show that the majority of Arts students $(96.1 \%)$ valued group feedback (whole class feedback) more than Science students $(38.5 \%)$. These results show that more individualized feedback was given to Arts students in an attempt from teachers to address their writing difficulties and that the Arts students felt more at ease and less intimidated to have their writing errors discussed in a whole class feedback. Thus, it is important for teachers to give the proper amount and type 
of feedback according to students' needs and preferences.

\subsubsection{Teacher Questionnaire Results}

The following table shows teacher's perspectives of the writing difficulties faced by their students and the following percentages stand for the "agree" responses.

Table 2. Percentages of teacher's responses regarding student difficulties

\begin{tabular}{lc}
\hline Difficulties faced by our ELI students & Percentage \\
\hline 1. Lack of ideas & 68 \\
2.Grammar difficulties & 88 \\
3.Vocabulary restriction & 96 \\
4.Topic inappropriateness & 40 \\
5. Lack of teacher's help (individual, whole-class feedback) & 32 \\
6. Incorrect use of mechanics of writing (spelling, punctuation, quotation, capitalization). & 92 \\
7. Unsuitable methods of teaching writing. & 52 \\
8. Time restriction. & 64 \\
9. Lack of clear assessment instruments and marking schemes. & 44 \\
10. Insufficient cognitive abilities (organize ideas on paper). & 64 \\
11. Correction of common errors on time and in a clear way. & 96
\end{tabular}

The writing difficulty which received the highest number of teacher's positive responses as applicable to their students was the lack of vocabulary $(96 \%)$ followed by difficulties in writing mechanics (92\%) (spelling, punctuation, capitalization) and then in grammar (88\%). It is significant here that these problems were similar to those stated earlier by Arts students as they were the group which suffered from most writing difficulties. This shows that Arts students were aware of their writing problems as much as their teachers.

Importantly still, correction of common errors on time and in a clear way as shown in the above table received the highest percentage (96\%) as a solution to student writing difficulties which shows that both students and teachers agreed on the importance of giving the appropriate feedback. Giving proper writing feedback is perceived by the researchers to be the reason behind the students' awareness of their difficulties which can lead to overcoming them.

Teachers added other writing problems faced by their students which are similar to the ones in previous research like poor language knowledge, lack of writing practice (Hafiz et al., 2018), lack of time to recycle and practice vocabulary, lack of student motivation (Alkubaidi, 2019), and lack of awareness of the importance of writing and finally the inability to elaborate main ideas and provide supporting details.

4.2 To Answer the Second Research Question Concerning the Most Common Writing Errors in Students' Writing Samples, the Following Table Shows the Types of Writing Errors, Their Numbers and Frequency Percentages in Both the Science and Arts Ssamples Respectively.

Table 3.Overall frequencies and percentages of Science \& Arts errors in relation to the three writing areas

\begin{tabular}{|c|c|c|c|c|c|c|c|c|c|c|c|c|c|}
\hline \multirow[t]{2}{*}{ Sec. } & \multicolumn{8}{|c|}{ Grammar \& Sentence Structure Errors (Syntax) } & \multicolumn{3}{|c|}{ Mechanics Errors } & \multirow{2}{*}{$\begin{array}{l}\begin{array}{l}\text { Semantic } \\
\text { Errors }\end{array} \\
\text { WW }\end{array}$} & \multirow{2}{*}{$\begin{array}{l}\text { Total } \\
\mathrm{T}\end{array}$} \\
\hline & $\mathrm{VF}$ & VT & $\mathrm{S}-\mathrm{V}$ & $\mathrm{P}$ & Prep & $\mathrm{A}$ & SS & Total & $\mathrm{SP}$ & $\mathrm{P}$ & Total & & \\
\hline \multirow[t]{3}{*}{ Science } & 24 & 9 & 17 & 28 & 39 & 37 & 82 & 236 & 111 & 86 & 197 & 62 & 495 \\
\hline & $5 \%$ & $2 \%$ & $3 \%$ & $6 \%$ & $8 \%$ & $\begin{array}{l}7 \\
\%\end{array}$ & $17 \%$ & $48 \%$ & $22 \%$ & $17 \%$ & $39 \%$ & $13 \%$ & $100 \%$ \\
\hline & \multicolumn{8}{|c|}{ Average number of errors per group } & & & & & $15.5 \%$ \\
\hline \multirow[t]{3}{*}{ Arts } & 50 & 24 & 3 & 18 & 39 & 34 & 126 & 294 & 227 & 84 & 311 & 29 & 634 \\
\hline & $8 \%$ & $4 \%$ & $\begin{array}{l}.04 \\
\%\end{array}$ & $3 \%$ & $6 \%$ & $5 \%$ & $20 \%$ & $46 \%$ & $36 \%$ & $13 \%$ & $49 \%$ & $5 \%$ & $100 \%$ \\
\hline & \multicolumn{8}{|c|}{ Average number of errors per group } & & & & & $19.8 \%$ \\
\hline
\end{tabular}

VF (verb form), VT (verb tense), S-V (subject-verb agreement), P (pronoun), Prep (preposition), A(article), SS (Sentence structure), SP (spelling), P (punctuation), WW (wrong word), T (total number of errors) 
The preceding table shows that student errors fell in the following types: verb form, verb tense, subject-verb agreement, pronoun reference, preposition, article, sentence structure, spelling, punctuation and word choice. In addition, the higher number of errors was in the Arts samples (634) with an average of (19.8\%) whereas the number of errors in the Science samples was (495) with an average of (15.5\%). This shows that Science students were higher in level than the Arts students. This result confirms the results reached earlier and the same justification applies here as well magnifying the influence of better schools, more education opportunities and family support on the student language level.

Furthermore, the table illustrates that the highest percentage of students' errors in both the Arts and Science samples was in spelling (mechanics) and sentence structure (syntax) respectively with a higher percentage of the frequency of these errors in the Arts samples. Basic grammatical aspects such as verb form and tense received as well higher percentages of errors in the Arts samples than in the Science ones. This reflected again the Arts students' lower proficiency of the English language. However, other grammar error types (subject-verb agreement, pronoun errors, preposition and article use), mechanics (punctuation) and semantic errors (word choice) received higher percentages of errors in the Science samples than in the Arts samples and preposition errors had the same number of errors in both samples. The justification for this is that Science students wrote more sentences than the Arts students trying to meet the minimum word count requirements which was 100 words; $93 \%$ of the students completed the writing task. On the other hand, the Arts students had to write at least 80 words; only $31 \%$ of the students completed the task. It is fair here to state that the more words students were requested to write, the number of errors would also increase.

The above table also shows that writing errors made by Arts students in descending order were mechanic errors (49\%) followed by grammar and syntactic errors (46\%) and finally semantic errors $(5 \%)$. On the other hand, Science students had more writing problems in grammar and syntactic areas $(48 \%)$ followed by mechanical errors $(39 \%)$ and finally the semantic errors (13\%).

Thus, based on the above results it can be said that Arts students have writing difficulties in mechanics especially spelling, and syntax particularly sentence structure. Comparatively, Science students have more semantic writing problems (word choice). In addition, grammar and punctuation errors are problematic areas for both sections. However, the lack of students' language competence or knowledge (Abdel Fattah et al., 2018) and the lack of practice of grammar rules (Alhaysony, 2012) are said to be the causes for all these types of errors. In addition, the seven-week span of the module did not seem to be sufficient to foster a great change in the student language level especially the writing skill. Furthermore, students' previous good grades in Level 1 were not reflective of their writing abilities.

Examples of students' writing errors are listed in the following table. 
Table 4. Examples of Science and Arts writing errors

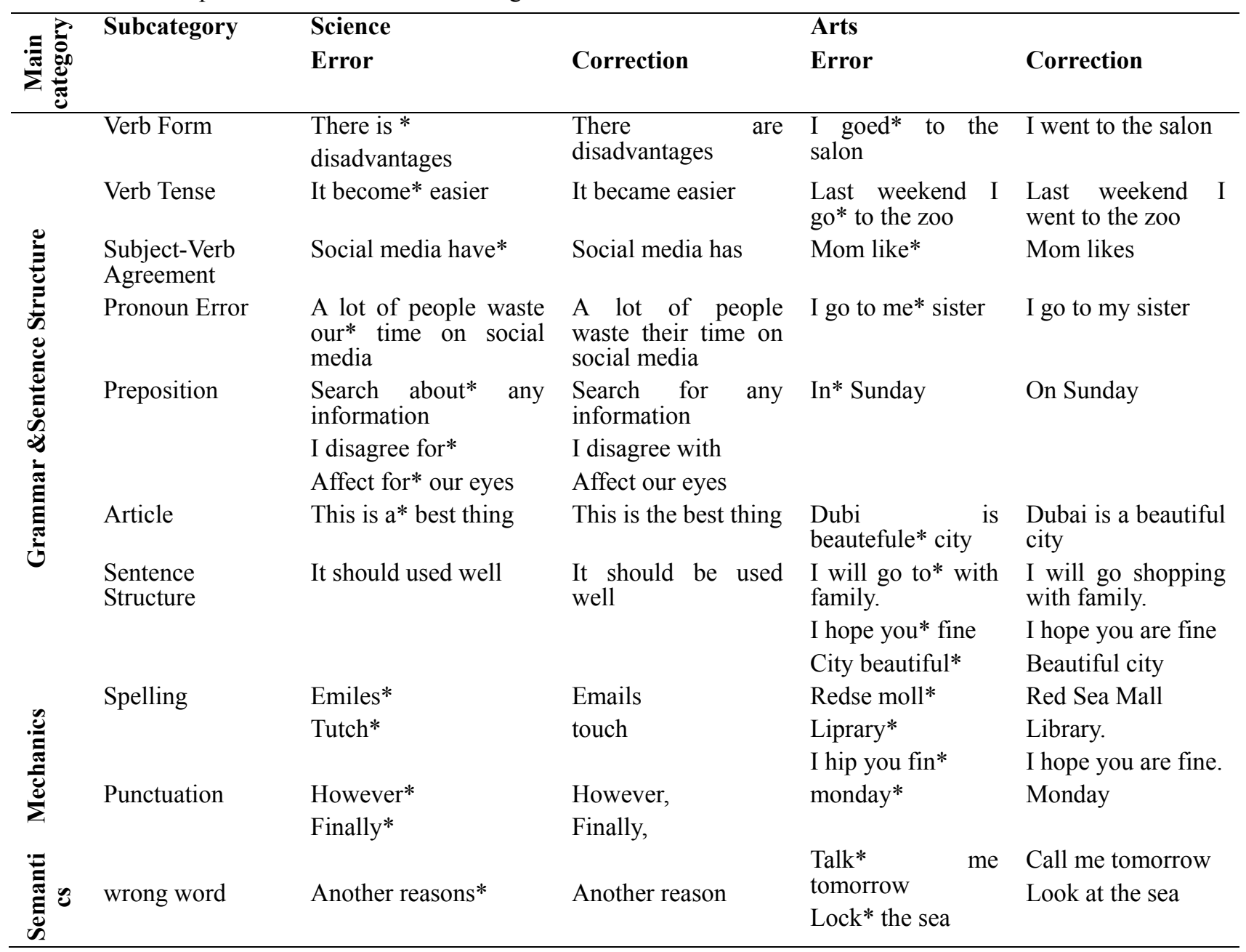

The above errors are just representative examples of the kinds of errors committed by students. These errors could be related to both interlingual and intralingual causes.

\subsubsection{Interlingual and Intralingual Causes}

Interlingual and intralingual effects are the main causes for student errors as illustrated in the literature section above. In the student writing samples, students' transference of Arabic grammar into the English sentence structure was obvious and could be seen as the first negative transfer of L1 as the following examples show. For instance, in Arabic there are no indefinite articles (a or an), thus, a sentence like "Dubai is beautiful city*" sounds correct for low proficient students. The Arabic sentence structure (i.e. city beautiful*) is another example of L1 transfer. Also, the misuse of preposition is partially affected by students' literal translation of the Arabic preposition into English. For instance, "Affect for our eyes*” is a literal translation of "يؤثر على أعينتان"; the preposition is found in the Arabic sentence whereas it does not exist in English. Added to that, many students resorted to literal translation from Arabic into English, the second negative transfer of L1, which resulted in semantic errors e.g. the confusion in using "another" and "other"; both of them have one equivalent word in Arabic which is "أخرى". This interference of Arabic causing writing errors was also found by Ababneh (2017), Hafiz et al. (2018), Sawalmeh (2013), and Alhaysony (2012) to be the main cause behind their Saudi students' writing errors.

Regarding the intralingual difficulties, examples were missing the "s" with the third person in the present tense "Mom like *" in addition to errors in forming the irregular verbs in the past tense such as "It become easier *". These errors were caused by the difficulty of the English language itself for different reasons: overlooking the exceptions to rules ("S" with third person) and incomplete rule application (simplification of the complicated rules as is the case with irregular verbs in the past tense e.g. goed* instead of went). 
Therefore, more exposure to the English language by encouraging students to speak English at home and with their friends in addition to effectively teaching the rules and conventions of writing and highlighting the differences between English and Arabic could help students reduce or overcome these errors.

4.3 To Further Investigate Other Causes for the Above Writing Errors and to Answer the Third Research Question, Teacher's Perspectives of These Causes are Provided in the Following Table.

Table 5. Percentages of teacher's responses in relation to causes of student's errors

\begin{tabular}{cc}
\hline Causes behind our students' errors & Percentage \\
\hline 1. Lack of conversation in the English language. & 84 \\
2. Rare reading in English. & 96 \\
3. Interference of Arabic language. & 76 \\
4. Carelessness. & 72 \\
5. Translation from the first language. & 80 \\
6. Over generalization and incomplete application of rules. & 68 \\
7. The difference between Arabic and English. & 76 \\
8. Inadequate application of primary language and writing mechanics. & 88 \\
9. Lack of immediate and sufficient written corrective feedback. & 48 \\
10. Inadequate time for writing. & 52 \\
11. Memorization of topics. & 84 \\
12. Unwillingness to learn. & 68 \\
13. Teaching approach doesn't foster learning because it is outdated. & 36
\end{tabular}

As the above table shows, the highest percentage of teacher's positive response "agree" was given to student's "rare reading in English" (96\%), and a very high percentage given to "students' lack of conversation in the English language" $(84 \%)$ as main reasons for writing errors. This study produced results which corroborate the findings of a great deal of the previous work in Ababneh (2017). The importance of reading in acquiring language systems was also assured by Krashen (2004) who believes that reading is a key factor to improve writing because students acquire language systems unconsciously. It will surely help to reduce the number of spelling errors. Alhaysony (2012) also argued that the lack of everyday exposure to the language is a main cause in language errors.

In addition, inadequate application of primary language and writing mechanics was the second main cause for writing errors $(88 \%)$. The third cause was memorization of writing topics $(84 \%)$. This finding also is in line with (Alkubaidi, 2019; Hafiz et al., 2018) who believed that their students memorized the content of writing to feel secure and have high grades. These reasons for memorization of writing paragraphs apply as well in our context with our students.

Direct translation from L1 received also a very high percentage of responses (80\%) as one of the main reasons for student errors. It is worthy to mention that "carelessness of students" and "unwillingness to learn" received approximately the same number of responses from teachers as causes for writing errors (72 and $68 \%$ respectively) showing the reliability of the research instrument and data as the two causes are almost the same in meaning and effect.

Other causes for students' errors were student unwillingness to write the first writing draft and follow the process of writing (planning, drafting and editing), lack of proper feedback, lack of motivation, the fear of making mistakes, and lack of training. T5 wrote "We don't allow them (students) adequate time for writing. Often times, learners don't get enough time as we ask them to even do the writing immediately, despite the L1 interference which makes them reluctant to write in English. Writing in L1 is often difficult for them, so why do we ask for immediate application of what they learn. Even if we give them the writing as homework, it is still considered immediate application." 
4.4 To Answer the Fourth Research Question in Relation to Remedial Actions to Eliminate Students' Writing Errors, Perceptions of Teachers can Be Shown from the Following Table.

Table 6. Percentages of teacher's responses regarding solutions for student writing errors

\begin{tabular}{cc}
\hline Solutions for student's writing errors & Percentage \\
\hline 1. Provide students with enough time to collect ideas about the topic through reading or watching a & 96 \\
short movie. & 100 \\
2. More training on the appropriate use of mechanics of writing. & 92 \\
3. Having clear assessment instruments (marking criteria). & 68 \\
4. Give students the chance to choose topics to write about. & 88 \\
5. More time for the pre-writing stage to generate ideas. & 96 \\
6. Correction of common errors on time and in a clear way. & 72 \\
7. Encourage students to discover their mistakes themselves and attempt to correct them. & 88 \\
8. Adopt various teaching methods that focus on active learning that suits the abilities and & \\
potentials of students. & 36 \\
9. Give students intensive exercises and homework assignments. & 84 \\
10. Provide students with a stimuli-rich learning environment to motivate them to learn and & \\
overcome challenges. & 44 \\
11. Collect the most difficult words and write them correctly on the white board. & 72 \\
12. Teach academic writing to help improve student's writing performance. & 76 \\
13. Teach more effectively the rules and conventions of writing. & 96 \\
14. Build confidence among students by enhancing their language abilities. & 72 \\
15. Learn writing using technology (videos...etc). & 96 \\
16. Make the teaching material enjoyable. & 92 \\
17. Implement pair and group work for more practice & 16 \\
18. Let students memorize topics. & 60
\end{tabular}

As is shown in the above table, the solutions that received the highest responses were: more student training on the appropriate use of mechanics of writing (100\%), building confidence among students by enhancing their language abilities (96\%), making the teaching material enjoyable $(96 \%)$, correction of common errors on time and clearly $(96 \%)$, having clear assessment rubrics $(92 \%)$, and implementation of pair and group work for more practice $(92 \%)$.

Other suggested solutions by teachers to lessen writing errors included more time for practice which is also advocated by Hafiz et al (2018), and Alhaysony (2012). T10 pointed "Time, time and more time. Our program is too condense and occurs with a very short period of time that's filled with practice, assignments, exams and other courses, which hinders their ability to comprehend and practice all the skills we try to develop in them. We need to elongate the span of our modules from quarters to semesters and create a smoother and calmer learning environment to them."

In addition, highlighting the difference between basic sentence structure in English and Arabic was mentioned by teachers as another solution to overcome errors. This is in line with Alasfour (2018). Furthermore, encouraging students to write simple sentences first and not to move to compound or complex sentences until they are given sufficient practice, teaching writing over a series of scaffolded stages ( modeled writing, shared writing, guided writing and independent writing), exposure to different writing genres with their sufficient practice, free writing, and providing incentives to writewere among teacher's suggestions "We should make grades for writing assignments and homeworks to force and encourage students to write."(T2).

As can be seen from the above discussion of results, this research's findings are in line with the findings of previous EA research on common writing errors of Saudi students: (Huwari \& Al-Khasawneh, 2013; Hafiz et al. 2018; Alkubaidi, 2019; Ababneh, 2017; Sawalmeh, 2013; Alhaysony, 2012; and Alasfour, 2018). These findings can be summarized in the following points:

1. Good educational opportunities, enough family support and student's entrance level of language affect the performance and the writing difficulties students face. 
2. Expressing ideas, connecting sentences and ideas together, lack of practice and motivation are main difficulties faced by the students.

3. Giving writing feedback should be based on students' level, needs and preference.

4. Proper writing feedback leads to students' awareness of their difficulties which can lead to overcoming them.

5. Writing is a problematic area for both Arts and Science students but errors fall in different areas depending on the level of students. Arts students have writing difficulties in mechanics especially spelling, and syntax particularly sentence structure. On the other hand, Science students have more semantic writing problems (word choice errors). However, grammar and punctuation errors are problematic areas for both sections.

6. Interlingual and intralingual factors are main causes behind students' errors.

7. Other causes of errors, as suggested by teachers, include lack of exposure to the language, inadequate application of primary language and writing mechanics, and memorization of writing topics.

8. Remedial actions, as suggested by teachers, are more student training on the mechanics of writing, building confidence among students by enhancing their language abilities, making the teaching material enjoyable, more time for practice and highlighting the difference between Arabic and English in sentence structure.

Limitations to this pilot study need to be acknowledged. First, being limited to female only participants, the generalizability of these findings was limited and gender specific. Therefore, the results would be more generalizable if both males and females were included. Second, the participants of the study were placed in level 2 of the English course. Thus, these findings cannot be extrapolated to all students in higher levels (level 3 and level 4). Last, the participants of the study were enrolled in a university preparatory year program. Therefore, the results may not be generalized to other groups of Saudi EFL students in other universities.

\section{Conclusions and Recommendations}

The purpose of the current study was to explore the most common English language writing errors of the Arts and Science students at a Saudi university, in an attempt to highlight their sources and possible remedies. Based on the error analysis of their writing samples, it was found that Arts students showed writing difficulties in mechanics especially spelling, and syntax, particularly sentence structure in comparison to Science students who had more semantic writing problems and demonstrated inept choice of words resulting in lexical errors. The errors were mainly found to be related to interlingual and intralingual sources. Other causes, based on the analysis of questionnaires' results, were lack of exposure to the English language, inadequate application of primary language and writing mechanics, memorization of writing topics and, the interference and direct translation from the native language (L1). Suggested remedial solutions included addressing student's common errors in a proper and timely manner, hence giving feedback in a way suitable to student's individual level, needs and preferences. Moreover, students should be familiarized with the differences in grammar and sentence structure between Arabic and English, provided more exposure to the target language (L2), as well as supported with teaching material which is relevant and enjoyable addressing errors found.

Based on the findings of the current study, the researchers present a number of suggestions for possible remedies for writing errors:

1. Increase the number of teaching weeks as writing is a skill that needs time for reinforcement and practice of grammar rules and writing conventions.

2. Address common writing errors repeatedly, either anonymously in a whole class discussion or individually, to eliminate fossilized errors. Individual feedback can be done over a one-minute conference with each student within teacher's office hours. In fact, both feedback techniques are quite efficient if done simultaneously along the course.

3. Use the peer correction method especially with pre-intermediate and intermediate students.

4. Encourage students to follow the writing process as the pre-writing stage helps students to generate ideas, which they lack, by brainstorming, reading a book or watching a related video (Ibnian, 2017).

5. Last but not least, it is important for teachers to revise their teaching methods and for course designers to decide what to focus on based on the above-mentioned results and findings especially highlighting the difference between Arabic and English grammar and adding more exercises to practice different 
writing skills.

Last but not least, it is recommended that further research be undertaken to investigate writing errors of foundation year students at more diverse levels in the course rather than focusing solely on level two students. Second, it would be interesting to compare writing errors of high school students and university students to have a better picture of how students develop their writing abilities and learn more about the possible causes of these errors.

\section{Acknowledgements}

This project was funded by the Deanship of Scientific Research (DSR), King Abdulaziz University, Jeddah, under grant no. (G: 1394-270-1440). The authors, therefore, acknowledge with thanks DSR technical and financial support.

\section{References}

Ababneh, I. (2017). Analysis of Written English: The Case of Female University Students in Saudi Arabia. International Journal of Social Science Studies, 5(4), 1-5. https://doi.org/10.11114/ijsss.v5i4.2264

Abdullah, N.A. J. (2017). An analysis of the grammatical errors made by FLEE 2113 students and the relation with National Pre-University Seminar (Npre US 2017) RHR Hotel, 23 Ogos 2017, E-ISBN:978-967-2122-11-1.

Abdel- Fattah, A. E., Abuleil, A. I. \& Habis, A. (2018). Error Analysis in a Saudi Context. Education and Linguistic Research, 4(1). Macrothink Institute. https://doi.org/10.5296/elr.v 4il.13069

Alasfour, Aisha Saud. (2018). Grammatical Errors by Arabic ESL Students: an Investigation of L1 Transfer through Error Analysis. Dissertations and Theses. Paper 4551. https://pdxscholar.library.pdx.edu/open_access_etds/4551.https://doi.org/10.15760/etd.6436

Al- Ghabra, I, M \& Najim. A.S. (2019). Analyzing Errors Committed in paragraph writing by Undergraduates. Journal of Language Teaching and Research, 10(2), 264-270. https://doi.org/10.17507/j 1tr.1002.07.

Alkubaidi, M. (2019). An Action Research on EFL Writing Dilemmas: A Case of Saudi Students and Instructors. Arab World English Journal, 10(3), 151-164. https://doi.org/10.24093/awej/vol10no3.10

Alhaysoni, M. (2012). An Analysis of Article Errors among Saudi Female EFL Students: A Case Study. Asian Social Science-Canadian Center of Science and Education, 8(12), 55-66. https://doi.org/10.5539/ass.v8n12p55

Al-husban, N. (2018). Error Analysis of Jordanian First-Year University students' English Language writing at Arab Open University- Case study. International Journal of Pedagogical Innovations, 6(1), 23-30. https://doi.org/ 10.12785/ijpi/060103

Atashian, S., \& Al-Bahri, K. (2018). Towards Arab Students' Grammatical Errors in Academic Writing \& their perceptions. Arab World English Journal. Proceedings of 1st MECTESOL Conference 2018. https://dx.doi.org/10.24093/awej/ MEC 1.10

Brown, H. D. (2000). Principles of language learning and teaching (4th ed.). White Plains, NY: Longman.

Corder, S.P. (1981). Error Analysis and Interlanguage. Oxford University press. London

Corder, S. P. (1974). Error Analysis: Perspectives on second language acquisition. London: Longman.

Corder, S.P. (1967). The significance of student's errors. International Review of Applied Linguistics in Language Teaching, 5(4), 161-170. https://doi.org/10.1515/iral.1967.5.1-4.161.

El-Koumy, A. S. (2004). Teaching and Learning English as a Foreign Language: A Comprehensive Approach. Educational Resources Information Centre (ERIC), USA. ISBN 977-316-082-3. Retrieved from https://www.academia.edu/3694962/Teachingand_Learning_English_as_a_Foreign_Language_A_Comp rehensive_Approach. 1 Jan, 2020

Hafiz, M. et al. (2018). Analysis of Syntactic Errors in English Writing: A case Study of Jazan University Preparatory Year Students. Journal of Education and Practice, 9(11), 113-120. ISSN 2222-1735 (Paper) ISSN 2222-288X (Online)

Huwari, I. F. \& Al-Khasawneh, F. M. (2013). The Reasons behind the Weaknesses of Writing in English among Pre-year Students' at Taibah University. English for Specific Purposes World, 14(38), 1-9. https://www.esp-world.info 
Ibnian, S.S.K. (2017). Writing Difficulties Encountered by Jordanian EFL Students. Aisan Journal of Humanities and Social Studies, 5(3), 197-206. https://www.ajouronline.com/index.php/AJHSS/article/view/4785/2478

Khansir, A.A. (2012). Error Analysis and Second Language Acquisition. Theory and Practice in Language Studies, 2(5), 1027-1032. https://doi.org/10.4304/tpls.2.5.1027-1032

Krashen, St. D. (2004). The Power of Reading: Insights from the Research, Libraries Unltd Incorporated. Retrieved from https://www.azquotes.com/author/81092-Stephen_D_Krashen. 13 Jan, 2020

Noor, H.H. (1996). English Syntactic Errors by Arabic Speaking Students. Resources in Education-Educational Resources Information Center (ERIC), 1441-1465. ID: 102341069

Odlin, T. (1989). Language Transfer, Cross-Linguistic Influence in Language Learning. Cambridge University Press. United Kingdom.

Richards, J.C. et al. (1992). Dictionary of language teaching and applied linguistics. Essex, Longman.

Sawalmeh, M.H.M. (2013). Error Analysis of Written En $\neg$ glish Essays: The case of Students of the Preparatory Year Program in Saudi Arabia. English for Specific Purposes World, 40(14), 1-17. https://www.esp-world.info

Siddiqui, M. A. (2015). Evaluating Capitalization Errors in Saudi Female Students' EFL Writing at Bisha University. Arab World English Journal, 8(1). https://doi. org/10.24093/awej/V016no1.19

Qaid, Y.A \& Ramamoorthy, L. (2011). A Study of Arabic Interference in Yemeni University Students' English Writing. Language

in India, $11(4)$ 28-37. http://www.languageinindia.com/april2011/yahiaarabicinterferencefinal.html

\section{Copyrights}

Copyright for this article is retained by the author(s), with first publication rights granted to the journal.

This is an open-access article distributed under the terms and conditions of the Creative Commons Attribution license (http://creativecommons.org/licenses/by/3.0/). 